\title{
Germline Mutations in RASA1 Are Not Found in Patients with Klippel-Trenaunay Syndrome or Capillary Malformation with Limb Overgrowth
}

\author{
N. Revencu ${ }^{a, b} \quad$ L.M.Boon ${ }^{a, c} \quad$ A. Dompmartin ${ }^{d} \quad$ P. Rieu ${ }^{\text {e }} \quad$ W.L. Busch ${ }^{9}$ \\ J. Dubois ${ }^{j}$ F. Forzanom ${ }^{m}$ J.M. van Hagen ${ }^{f}$ S. Halbach ${ }^{\text {h }}$ A. Kuechler ${ }^{n}$ \\ A.M.A. Lachmeijer ${ }^{f} \quad$ J. Lähdel L. Russellk K.O.J.Simolal J.B. Mulliken ${ }^{\mathrm{i}}$ \\ M. Vikkula ${ }^{a}$ \\ a Laboratory of Human Molecular Genetics, de Duve Institute, ${ }^{b}$ Center for Human Genetics, and \\ 'Vascular Anomalies Center, Division of Plastic Surgery, Cliniques universitaires St Luc, \\ Université catholique de Louvain, Brussels, Belgium; ${ }^{\mathrm{d}}$ Department of Dermatology, Université de Caen \\ Basse Normandie, CHU Caen, Caen, France; ${ }^{e}$ Kinderchirurgie, UMC, St-Rabdoud, University of Nijmegen, \\ Nijmegen, and fDepartment of Clinical Genetics, VU University Medical Center, Amsterdam, The Netherlands; \\ ${ }^{g}$ Northwest Perinatal Center, Portland, Oreg., h Department of Human Genetics, University of Chicago, \\ Chicago, Ill., and 'Department of Plastic and Oral Surgery, Children's Hospital, Harvard Medical School, \\ Boston, Mass., USA; 'Department of Medical Imaging, Sainte-Justine Mother-Child University Hospital, and \\ kDepartment of Medical Genetics, McGill University Health Centre, Montreal, Que., Canada;

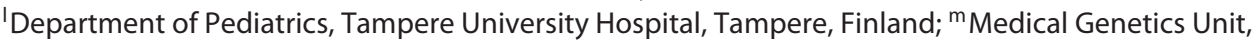 \\ Galliera Hospital, Genova, Italy; ${ }^{\mathrm{n}}$ Institut für Humangenetik, Universitätsklinikum Essen, Essen, Germany
}

\section{Key Words}

Klippel-Trenaunay syndrome - Capillary malformation . Capillary malformation-arteriovenous malformation . Overgrowth - Parkes Weber syndrome - RASA1 . p120RASGAP

\begin{abstract}
The RASA 1 gene encodes p120RASGAP, a multidomain cytoplasmic protein that acts as a negative regulator of the RAS signalling pathway. Heterozygous loss-of-function RASA1 mutations were identified in patients with Parkes Weber syndrome and multifocal capillary malformations. This syndrome is characterised by a capillary blush on an extremity, arteriovenous microfistulas, and bony and soft tissue hypertrophy. The aim of this study was to test RASA 1 in 2 disorders characterised by asymmetric limb enlargement and vascular
\end{abstract}

\section{KARGER}

E-Mail karger@karger.com

www.karger.com/msy malformations, namely Klippel-Trenaunay syndrome and regional capillary malformation with overgrowth. We did not identify any clear pathogenic change in these patients. Thus, besides clinical and radiological criteria, RASA1 testing constitutes an additional tool to differentiate Parkes Weber syndrome of capillary malformation-arteriovenous malformation (CM-AVM) from overlapping disorders.

Copyright $\odot 2013$ S. Karger AG, Basel

Overgrowth syndromes are a heterogeneous group of disorders, characterised by generalised or localised enlargement of a body part. A practical classification and a precise diagnosis are important for proper management, genetic counselling, and research. Vascular malformations are a component of several of these disorders, including Klippel-Trenaunay, Parkes Weber, congenital (c) 2013 S. Karger AG, Basel

1661-8769/13/0044-0173\$38.00/0 
Fig. 1. a Patient with Parkes Weber syndrome and RASA1 mutation. b Patient with KTS (patient 4 in table 1). c Patient with CMO (patient 26 in table 1).
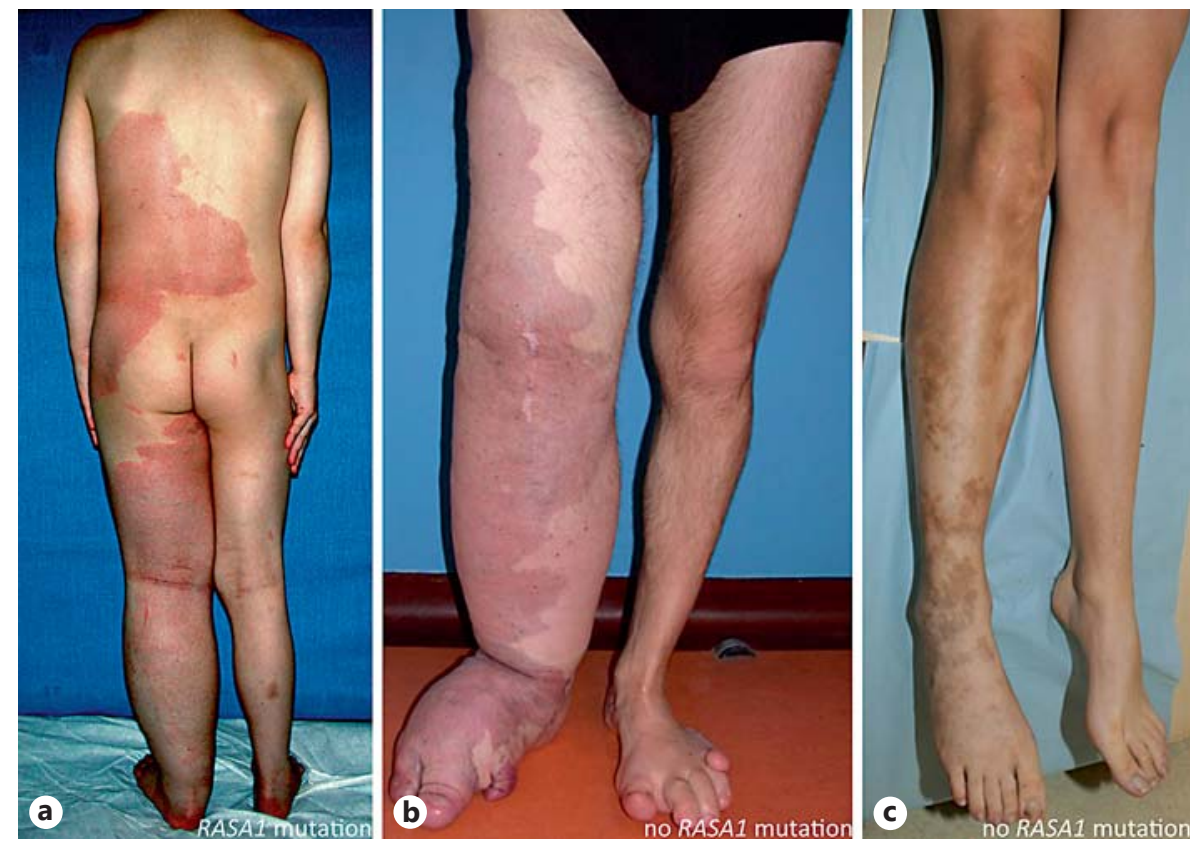

lipomatous overgrowth, vascular malformations and epidermal nevi syndrome (CLOVES) and Proteus syndromes. The clinical and radiological overlap between these conditions can be confusing, especially in young children; diagnosis would be greatly facilitated if a genetic test were available.

Parkes Weber syndrome is a congenital, combined fast-flow vascular malformation of a limb and is characterised by a cutaneous blush with underlying multiple arteriovenous microfistulas with soft tissue and bony hypertrophy [Mulliken and Young, 1988]. We showed that heterozygous inherited or de novo loss-of-function mutations in the RASA1 gene cause Parkes Weber syndrome (OMIM 608355) in association with multifocal capillary malformations (fig. 1a) [Eerola et al., 2003; Revencu et al., 2008]. Thus, Parkes Weber syndrome is on the phenotypic spectrum of capillary malformation - arteriovenous malformation (CM-AVM; OMIM 163000).

Since the description by Parkes Weber more than 100 years ago [Parkes Weber, 1907, 1908, 1918], Parkes Weber syndrome has often been confused with Klippel-Trenaunay syndrome (KTS; OMIM 149000), which is the most commonly used diagnosis for an overgrowth syndrome with vascular malformations. KTS was recognised as a distinct entity by Klippel and Trenaunay [1900]. It is a rare, congenital, combined slow-flow vascular malformation with abnormal deep venous network, varicosities of abnormal distribution (lateral venous anomaly), and soft tissue and bony hypertrophy [Boyd et al., 1984; Mulliken and Young, 1988]. There is considerable clinical variability among patients with KTS, and different clinical criteria are used in the literature. It is considered to be sporadic, and the aetiology remains unknown.

The distinction between Parkes Weber and KTS is important, as the management and the risks for offspring are different. Due to the clinical overlap between the 2 entities, we decided to test patients with KTS for germline RASA 1 mutations. We also included patients with regional capillary malformation in an overgrown limb (CMO) with or without dilated veins, and without lymphatic malformations, venous malformations or arteriovenous fistulas.

\section{Materials and Methods}

\section{Patient Recruitment}

In this study, we included patients with limb overgrowth and vascular malformations that can mimic Parkes Weber syndrome (fig. 1a), namely KTS (fig. 1b), and regional CMO with or without dilated veins (fig. 1c). We excluded patients with CLOVES or Proteus syndrome, as the phenotypes are different. Clinical data, photographs and blood on EDTA or DNA samples from patients and their families were collected. Thirty patients from 14 centres participated in the study. N.R., L.M.B., and M.V. reviewed all the clinical files. Patients with capillary, lymphatic and venous malformations on a limb, with bony and soft tissue hypertrophy were considered to have KTS, according to the classification of the In- 
Table 1. Clinical phenotype and RASA1 changes observed in patients with KTS and patients with CMO

\begin{tabular}{|c|c|c|c|c|c|c|}
\hline Patient & Diagnosis & Sex & Age, years & Location & $\begin{array}{l}\text { Additional } \\
\text { features }\end{array}$ & RASA1 change \\
\hline 1 & KTS & $\mathrm{F}$ & 19 & RLE & & - \\
\hline 2 & KTS & M & 10 & LLE & & - \\
\hline 3 & KTS & M & 7 & RLE and trunk & & - \\
\hline 4 & KTS & M & 43 & RLE & macrodactyly & - \\
\hline 5 & KTS & M & 21 & LLE & & - \\
\hline 6 & KTS & $\mathrm{F}$ & 26 & RLE & & - \\
\hline 7 & KTS & M & 43 & LLE & $\begin{array}{l}\text { insignificant } \\
\text { microfistules }\end{array}$ & - \\
\hline 8 & KTS & M & 42 & LLE & & - \\
\hline 9 & KTS & M & 6 & LLE & $\begin{array}{l}\text { feet syndactyly, } \\
\text { macrodactyly }\end{array}$ & - \\
\hline 10 & KTS & $\mathrm{F}$ & 21 & RLE & & - \\
\hline 11 & KTS & M & 53 & both LE & feet syndactyly $2 / 3$ & $\begin{array}{l}\text { p.A99V; } \\
\text { rs111840875 }\end{array}$ \\
\hline 12 & KTS & M & 21 & LUE & & $\begin{array}{l}\text { p.A99V; } \\
\text { rs111840875 }\end{array}$ \\
\hline 13 & KTS & $\mathrm{F}$ & 29 & 4 extremities & & - \\
\hline 14 & $\mathrm{CMO}$ & M & 35 & RLE & & - \\
\hline 15 & $\mathrm{CMO}$ & $\mathrm{F}$ & 40 & RLE & & - \\
\hline 16 & $\mathrm{CMO}$ & $\mathrm{M}$ & 10 & right hemihypertrophy & telangiectasias & - \\
\hline 17 & $\mathrm{CMO}$ & $\mathrm{M}$ & 10 & RLE & & - \\
\hline 18 & $\mathrm{CMO}$ & $\mathrm{F}$ & 9 & RLE and trunk & & - \\
\hline 19 & $\mathrm{CMO}$ & $\mathrm{F}$ & 6 & RLE & & - \\
\hline 20 & $\mathrm{CMO}$ & M & 9 & both LE, RLE>LLE & & - \\
\hline 21 & $\mathrm{CMO}$ & $\mathrm{F}$ & 52 & RLE & dilated veins & $\begin{array}{l}\text { c. } 540-27 \mathrm{G}>\mathrm{A} ; \\
\mathrm{rs} 13157168\end{array}$ \\
\hline 22 & $\mathrm{CMO}$ & M & 28 & right hemihypertrophy & & - \\
\hline 23 & $\mathrm{CMO}$ & $\mathrm{M}$ & 27 & RLE & dilated veins & - \\
\hline 24 & $\mathrm{CMO}$ & $\mathrm{F}$ & 20 & LLE & dilated veins & - \\
\hline 25 & $\mathrm{CMO}$ & M & 1 & LUE and trunk & & - \\
\hline 26 & $\mathrm{CMO}$ & $\mathrm{M}$ & 17 & RLE & dilated veins & - \\
\hline 27 & $\mathrm{CMO}$ & M & 29 & LLE & dilated veins & - \\
\hline 28 & $\mathrm{CMO}$ & $\mathrm{F}$ & 20 & LLE & & - \\
\hline 29 & $\mathrm{CMO}$ & $\mathrm{M}$ & 20 & LLE & dilated veins & - \\
\hline 30 & $\mathrm{CMO}$ & M & 30 & LLE & dilated veins & - \\
\hline
\end{tabular}

RLE = Right lower extremity; LLE = left lower extremity; LUE = left upper extremity. Numbering of nucleotides is based on the cDNA sequence NM_002890.1 with A of the start ATG codon as +1.

ternational Society for the Study of Vascular Anomalies (ISSVA) [Enjolras et al., 2007]. Patients with regional CMO were considered to be a distinct entity [Enjolras et al., 2004]. Informed consent was obtained from all patients, and the ethics committee of the medical faculty of Université catholique de Louvain, Brussels, Belgium, approved the research protocol.

\section{Mutational Analysis of the RASA1 Gene}

DNA was extracted from blood leukocytes using Puregene DNA Isolation Kit (Gentra Sytems). Primers were designed using RefSeq accession number NM_002890.1 for all the 25 exons of the RASA 1 gene, including exon-intron boundaries. After polymerase chain reaction amplification, the amplicons were screened using denaturing high-performance liquid chromatography (DHPLC) on the WAVE $3500 \mathrm{HS}$ system (Transgenomic) or high-resolution melting (HRM) on the Light Cycler 480 System (Roche). Each sample with an abnormal elution or melting profile was amplified by polymerase chain reaction, purified (Qiagen) and sequenced on a CEQ2000 fluorescent capillary sequencer (Beckman Coulter) or on an ABI prism 3130xl Genetic Analyser (Applied Biosystems). The sequence data generated was analysed using the Sequencher DNA software (Gene Codes Corporation). The changes identified were checked against the NCBI SNP database to identify known single nucleotide polymorphisms. 


\section{Results}

\section{Phenotypic Spectrum}

The phenotype of each patient is detailed in table 1 . Thirteen patients ( 4 females and 9 males) with KTS and 17 patients (6 females and 11 males) with regional CMO with or without dilated veins were included. The patients had disturbed growth in length and/or girth in bony and soft tissues, in association with the vascular malformation on the affected segment.

\section{Genetic Studies}

We analysed all the 25 exons and exon/intron boundaries of the RASA1 gene (NM_002890.1). The genetic results are summarised in table 1 . No clear pathogenic change was identified. Known polymorphisms were identified in 2 patients with KTS and in one patient with $\mathrm{CMO}$

\section{Discussion}

Many patients with a vascular anomaly of the limb associated with overgrowth are diagnosed as having KTS. Other diagnoses need to be considered, the closest being Parkes Weber syndrome and regional CM involving an entire limb with hypertrophy. The differential diagnosis between these entities can be difficult, especially in young children.

Parkes Weber syndrome is a fast-flow anomaly, usually diagnosed by Doppler ultrasonography. Yet, the diagnosis of the fast-flow nature may not be obvious at birth, even for a radiologist trained in vascular anomalies. We showed that Parkes Weber syndrome with multifocal CMs is caused by RASA1 mutation, whereas Parkes Weber syndrome without multifocal CMs is not [Revencu et al., 2008].

Due to the clinical similarities among the entities with vascular malformation on a hypertrophied limb, we decided to test RASA 1 in patients with KTS and in patients with regional CMO. Based on the criteria proposed by Oduber et al. [2008], these 2 groups of patients would be classified as KTS. We prefer to consider these 2 separate entities and reserve the term KTS for patients with slowflow combined vascular malformations comprising capillary, lymphatic and venous malformations, as introduced by Mulliken and Young [1988] and later incorporated in the ISSVA classification [Enjolras et al., 2007].

All the coding parts and the intron/exon boundaries of RASA1 were analysed for germline mutations in 13 pa- tients with KTS and 17 patients with CMO with or without dilated veins. Although gender distribution is usually equal in patients with KTS, in our series, the M/F ratio was $9 / 4$. Similar proportion was observed in patients with CMO (11/6). We identified known polymorphisms in 3 patients, but no pathogenic changes. Thus, RASA1 mutations are not the pathophysiological cause of these 2 entities, and RASA1 testing becomes an important tool for the differential diagnosis of patients with limb overgrowth and vascular anomalies. RASA1 mutation indicates to Parkes Weber syndrome on the spectrum of CM-AVM.

A precise diagnosis is clinically important as these conditions are managed differently, and the risks for offspring also differ. Patients with Parkes Weber syndrome are at risk of ulceration, cardiac overload and, sometimes, cardiac failure [Revencu et al., 2008], whereas patients with KTS are at risk of developing superficial thrombophlebitis, deep venous thrombosis, pulmonary thromboembolism, and infection [Kulungowski and Fishman, 2011]. Leg length discrepancy is an important issue in both KTS and Parkes Weber syndrome. However, while epiphysiodesis is considered in patients with KTS with a discrepancy larger than $2 \mathrm{~cm}$ of the legs, it should be avoided in patients with Parkes Weber syndrome, as it can aggravate the fast-flow lesions, especially if located near the knee [Enjolras et al., 2004]. Usually no orthopedic treatment is necessary in patients with CMO. Debulking procedures to remove excess girth are possible in KTS. This approach should be avoided in patients with Parkes Weber syndrome because of the underlying arteriovenous microfistulas [Kulungowski and Fishman, 2011].

Often the 2 eponyms are combined as 'Klippel-Trenaunay-Weber' syndrome to describe patients with Klippel-Trenaunay features and arteriovenous fistulae, increasing the confusion between the 2 entities [Viljoen, 1988; Ceballos-Quintal et al., 1996]. KTS is not associated with significant arteriovenous communications [Lindenauer, 1965; Servelle, 1985; Alomari et al., 2010]. One family reported to have Klippel-Trenaunay-Weber syndrome [Ceballos-Quintal et al., 1996] was proven to have Parkes Weber syndrome by the identification of a RASA1 mutation in the child [Revencu et al., 2008]. There are several other patients that would be interesting to screen for RASA1 mutations among the 1,500 cases purported to be KTS in the literature. Most of the cases occur sporadically, yet some are familial, although this is subject to debate [Cohen, 2000]. There is an increased tendency for CMs among relatives of these patients. Aelvoet et al. [1992] analysed 86 patients with 'Klippel-Trenaunay' 
syndrome, and found 2 who had a second-degree relative with KTS. All the affected individuals were reported to have multiple spider naevi or capillary stains. In addition, 4 unrelated individuals with 'Klippel-Trenaunay' syndrome had relatives with multiple capillary lesions. Similarly, in the family reported by Craven and Wright [1995], 2 members had 'Klippel-Trenaunay' syndrome and several relatives had numerous naevi flammei. Thus, these cases are likely to be Parkes Weber syndrome of CMAVM. Careful evaluation of the so-called 'familial Klippel-Trenaunay' is necessary and RASA1 should be screened.

The aetiology of KTS is unknown. A patient with an apparently balanced $(5 ; 11)(\mathrm{q} 13.3 ; \mathrm{p} 15.1)$ translocation was reported [Whelan et al., 1995]. Tian et al. [2004] localised the breakpoint on $5 \mathrm{q} 13.3$ in the promoter of the $A G G F 1$ gene and identified a substitution, E133K, in 5 of 130 patients with KTS. This change was subsequently found in healthy controls with a frequency of $2.2-3.3 \%$ by 2 groups, suggesting a polymorphism without pathophysiological effects [Barker et al., 2006; Gutierrez et al., 2006]. Several hypotheses have been proposed to explain KTS, such as multifactorial, paradominant inheritance or a mosaic mutation. We think that the most plausible explanation is a mutation in a mosaic state in a gene that would be lethal when mutated in a non-mosaic state. We demonstrated this phenomenon for the most frequent somatic TIE2 mutation seen in sporadic venous malformations that has never been seen in inherited venous malformations [Limaye et al., 2009a, b]. Somatic mutations in components of the PI3K-AKT pathway have now been identified in various segmental or patchy overgrowth syndromes: an activating $A K T 1$ mutation in patients with Proteus syndrome, and activating PIK3CA mutations in patients with CLOVES syndrome, megalencephaly-capillary malformation syndrome, megalencephaly-polymicrogyria-polydactyly-hydrocephalus syndrome, and in patients with mosaic overgrowth with fibroadipose hyperplasia [Lindhurst et al., 2011, 2012; Kurek et al., 2012; Riviere et al., 2012]. In the current study, we only looked for germline RASA 1 mutations; thus, a mosaic mutation would have been missed. Exome sequencing of the DNA extracted from affected and unaffected tissues from patients with these pathologies is needed to clarify the aetiology. The PI3K-AKT pathway is of potential interest.

\section{Conclusion}

KTS and regional CMO, with or without dilated veins, are not caused by germline mutations in the RASA 1 gene. Thus, RASA 1 testing is an additional tool, besides clinical and radiological features, for the evaluation of patients with a vascular malformation and hypertrophied limb.

\section{Acknowledgements}

We are grateful to all the family members for their invaluable contributions. These studies were supported by: Cliniques universitaires Saint-Luc, Université catholique de Louvain, and Fonds de la Recherche Scientifique Médicale (FRSM) to N.R.; the Interuniversity Attraction Poles initiated by the Belgian Federal Science Policy, network 7/43, Concerted Research Actions (A.R.C.) - Convention No 07/12-005 of the Belgian French Community Ministry, the F.R.S.-FNRS (Fonds de la Recherche Scientifique), and la Communauté française de Wallonie-Bruxelles to M.V. The study was also supported by la Lotterie nationale, Belgium. The authors thank Anne Van Egeren and Antonella Mendola for expert technical assistance, and Ms Liliana Niculescu for secretarial help.

\section{References}

Aelvoet GE, Jorens PG, Roelen LM: Genetic aspects of the Klippel-Trenaunay syndrome. $\mathrm{Br}$ J Dermatol 126:603-607 (1992).

-Alomari AI, Orbach DB, Mulliken JB, Bisdorff A, Fishman SJ, et al: Klippel-Trenaunay syndrome and spinal arteriovenous malformations: an erroneous association. AJNR Am J Neuroradiol 31:1608-1612 (2010).

Barker KT, Foulkes WD, Schwartz CE, Labadie C, Monsell F, et al: Is the E133K allele of VG5Q associated with Klippel-Trenaunay and other overgrowth syndromes? J Med Genet 43:613614 (2006).

No Germline RASA1 Mutation in KTS or CM with Limb Overgrowth
Boyd JB, Mulliken JB, Kaban LB, Upton J 3rd, Murray JE: Skeletal changes associated with vascular malformations. Plast Reconstr Surg 74:789-797 (1984)

Ceballos-Quintal JM, Pinto-Escalante D, Castillo-Zapata I: A new case of Klippel-Trenaunay-Weber (KTW) syndrome: evidence of autosomal dominant inheritance. Am J Med Genet 63:426-427 (1996).

Cohen MM Jr: Klippel-Trenaunay syndrome. Am J Med Genet 93:171-175 (2000).

Craven N, Wright AL: Familial Klippel-Trenaunay syndrome: a case report. Clin Exp Dermatol 20:76-79 (1995).
Eerola I, Boon LM, Mulliken JB, Burrows PE, Dompmartin A, et al: Capillary malformation-arteriovenous malformation, a new clinical and genetic disorder caused by RASA1 mutations. Am J Hum Genet 73:1240-1249 (2003).

Enjolras O, Chapot R, Merland JJ: Vascular anomalies and the growth of limbs: a review. J Pediatr Orthop B 13:349-357 (2004).

Enjolras O, Wassef M, Chapot R: Introduction: ISSVA classification, in Press CU (ed): Color Atlas of Vascular Tumors and Vascular Malformations, pp 1-11 (University Press, Cambridge 2007). 
Gutierrez S, Magano L, Delicado A, Mori MA, de Torres ML, et al: The G397A (E133K) change in the AGGF1 (VG5Q) gene is a single nucleotide polymorphism in the Spanish population. Am J Med Genet A 140:2832-2833 (2006).

Klippel M, Trenaunay P: Memoires originaux: $\mathrm{du}$ noevus variqueux osteo-hypertrophique. Arch Gen Med III:641-672 (1900).

Kulungowski AM, Fishman SJ: Management of combined vascular malformations. Clin Plast Surg 38:107-120 (2011)

Kurek KC, Luks VL, Ayturk UM, Alomari AI, Fishman SJ, et al: Somatic mosaic activating mutations in PIK3CA cause CLOVES syndrome. Am J Hum Genet 90:1108-1115 (2012).

Limaye N, Boon LM, Vikkula M: From germline towards somatic mutations in the pathophysiology of vascular anomalies. Hum Mol Genet 18:R65-R74 (2009a).

Limaye N, Wouters V, Uebelhoer M, Tuominen M, Wirkkala R, et al: Somatic mutations in angiopoietin receptor gene TEK cause solitary and multiple sporadic venous malformations. Nat Genet 41:118-124 (2009b).
Lindenauer SM: The Klippel-Trenaunay syndrome: varicosity, hypertrophy and hemangioma with no arteriovenous fistula. Ann Surg 162:303-314 (1965).

Lindhurst MJ, Sapp JC, Teer JK, Johnston JJ, Finn EM, et al: 2011. A mosaic activating mutation in AKT1 associated with the Proteus syndrome. N Engl J Med 365:611-619 (2011).

- Lindhurst MJ, Parker VE, Payne F, Sapp JC, Rudge S, et al: Mosaic overgrowth with fibroadipose hyperplasia is caused by somatic activating mutations in PIK3CA. Nat Genet 44: 928-933 (2012).

Mulliken JB, Young AE: Vascular Birthmarks: Hemangiomas and Malformations (WB Saunders, Philadelphia 1988).

Oduber CE, van der Horst CM, Hennekam RC: Klippel-Trenaunay syndrome: diagnostic criteria and hypothesis on etiology. Ann Plast Surg 60:217-223 (2008).

Parkes Weber F: Angioma formation in connection with hypertrophy of limbs and hemihypertrophy. Br J Dermatol 19:231-235 (1907).

Parkes Weber F: Haemangiectatic hypertrophies of the foot and lower extremity. Med Press (Lond) 136:261 (1908).

Parkes Weber F: Hemangiectatic hypertrophy of limbs-congenital phlebarteriectasis and socalled congenital varicose veins. Br J Child Dis 15:13-17 (1918).
Revencu N, Boon LM, Mulliken JB, Enjolras O, Cordisco MR, et al: Parkes Weber syndrome, vein of Galen aneurysmal malformation, and other fast-flow vascular anomalies are caused by RASA1 mutations. Hum Mutat 29:959965 (2008).

Riviere JB, Mirzaa GM, O’Roak BJ, Beddaoui M, Alcantara D, et al: De novo germline and postzygotic mutations in AKT3, PIK3R2 and $P I K 3 C A$ cause a spectrum of related megalencephaly syndromes. Nat Genet 44:934-940 (2012)

-Servelle M: Klippel and Trenaunay's syndrome. 768 operated cases. Ann Surg 201:365-373 (1985).

- Tian XL, Kadaba R, You SA, Liu M, Timur AA, et al: Identification of an angiogenic factor that when mutated causes susceptibility to Klippel-Trenaunay syndrome. Nature 427:640645 (2004).

-Viljoen DL: Klippel-Trenaunay-Weber syndrome (angio-osteohypertrophy syndrome). J Med Genet 25:250-252 (1988).

-Whelan AJ, Watson MS, Porter FD, Steiner RD: 1995. Klippel-Trenaunay-Weber syndrome associated with a 5:11 balanced translocation. Am J Med Genet 59:492-494 (1995). 